\title{
Metallographic Comparison of Copper and Brass Plasma Reactor Electrodes After a Month of Operation
}

\author{
Sebastian Gnapowski ${ }^{1 *}$, Elżbieta Kalinowska-Ozgowicz ${ }^{1}$, Aleksandra Pietraszek ${ }^{1}$ \\ ${ }^{1}$ Fundamentals of Technology Faculty, Lublin University of Technology, Nadbystrzycka street 38D, 20-618 \\ Lublin, Poland \\ * Corresponding author's e-mail: sgnapowski@wp.pl
}

\begin{abstract}
Many researchers from around the world are looking for better and cheaper means of ozone production. One of the methods of increasing the efficiency of ozone production is the use of a rotating electrode presented in this paper. Experiments were carried out which showed that the most important parameters are the materials used in the electrodes and the condition of their surface. The metallographic investigations of the electrodes after continuous work for a month were made, which show how the raids layers are formed. As a result of working in a highly oxidizing environment, the electrode is oxidized in a process of chemical corrosion. It is obvious that the layer of corrosion products created during the work of the plasma reactor isolates the surface of the electrode, which reduces the intensity of the electric field, causing a decrease in the amount of plasma generated, which reduces the concentration of ozone during this process. The dynamics of the plasma generation process and the type of electrode material working in changing process conditions are the decisive factors influencing the concentration of ozone produced. The influence of the medium, which is the electrode material, depends mainly on its resistance to corrosion in the environment of dynamically changing conditions, e.g. electrode rotation, oxygen flow through the rotating electric field and the month-long working time of the plasma reactor.
\end{abstract}

Keywords: copper, $\mathrm{Cu}-\mathrm{Zn}-\mathrm{Pb}$, raids layers, metals, electrodes, ozone, plasma reactor.

\section{INTRODUCTION}

The most common case of chemical corrosion is gas corrosion occurring in environments containing oxygen, air, nitrogen, sulfur and its compounds. Gas corrosion is the result of a chemical reaction of oxidation $[1 \div 3]$. Heating metal products in an atmosphere of air causes their oxidation $[4 \div 6]$. Oxygen from the air reacts with metal to form a thin layer of oxide separating the metallic surface from the gaseous environment. Depending on the nature of the structure of the oxide layer forming which determines the possibility of the oxygen atom's contact with metal atoms, four mechanisms of the formation of oxides on metals are distinguished $[7 \div 9]$. The speed of elementary partial processes of the oxidation reaction of metals and alloys depends to a different degree on temperature and pressure. The slowest elementary process determines the speed of the entire reaction [10]. The oxidation times of individual metals in the air show significant variation (Table 1). The rate of oxidation depends to a large extent on the purity of the material, the condition of its surface and the pollution of the atmosphere. The condition of the metal surface significantly influences the rate of corrosion. In particular, acceleration of the corrosion course may be due to the preferential crystallographic orientation of the metal surface exposed to the oxidizing atmosphere. Larger dimensions and more irregular shapes of unevenness created as a result of inaccurate surface treatment of the metal or alloy make it difficult to evenly build up the scale and its plastic deformation without cracks and micro-scales. This promotes the acceleration of the gas corrosion process [11]. 
The composition of the atmosphere determines the nature of chemical reactions and the magnitude of corrosion damage. The presence of oxidants may be accompanied by aggressive vapors or other similar gases. The most common gas mixtures causing intensive corrosion are: air, steam, carbon compounds, e.g. mixtures (CO $\mathrm{CO}_{2}$ ), hydrocarbons, sulfur compounds, $(\mathrm{H} 2 \mathrm{~S}$, $\mathrm{SO}_{2}$ and $\mathrm{SO}_{3}$ ). exhaust gases containing mainly sulfur and ashes, as well as halogens, nitrogen and ammonia $[9 \div 10]$.

\section{MATERIALS AND METHODS}

Ozone is widely used in industry and producers strive to ensure that its production is stable and as effective as possible [12 $\div 16]$. The most frequent phenomena and processes during plasma generation were in the environment and explained. During these studies, decreases in concentration were observed $[17 \div 19]$. The rotating electrode is not responsible for phenomena also observed in reactors of other types $[20 \div 23]$. The factor that determined the investigations of electrodes used in the plasma reactor was the decreasing efficiency of the device during ozone production while maintaining constant process parameters [24]. The only noticeable change during reactor operation was the change

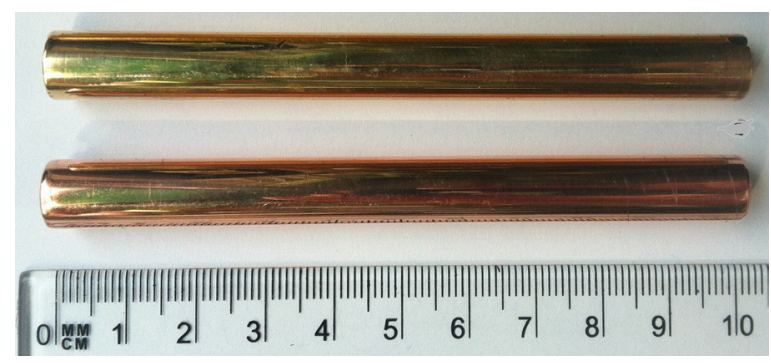

Fig. 1. Photograph of electrodes for operation in a plasma reactor, a) copper electrode, b) alloy electrode $\mathrm{Cu}-\mathrm{Zn}-\mathrm{Pb}$

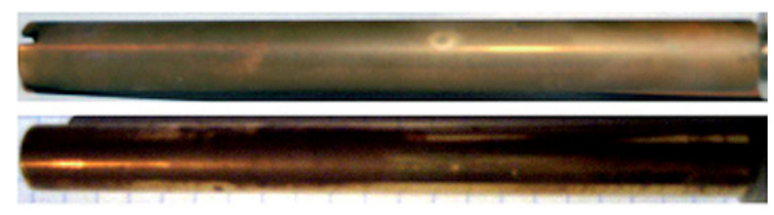

Fig. 2. Photograph of electrodes after monthly use in a plasma reactor a) copper electrode, b) $\mathrm{Cu}-\mathrm{Zn}-\mathrm{Pb}$ alloy electrode

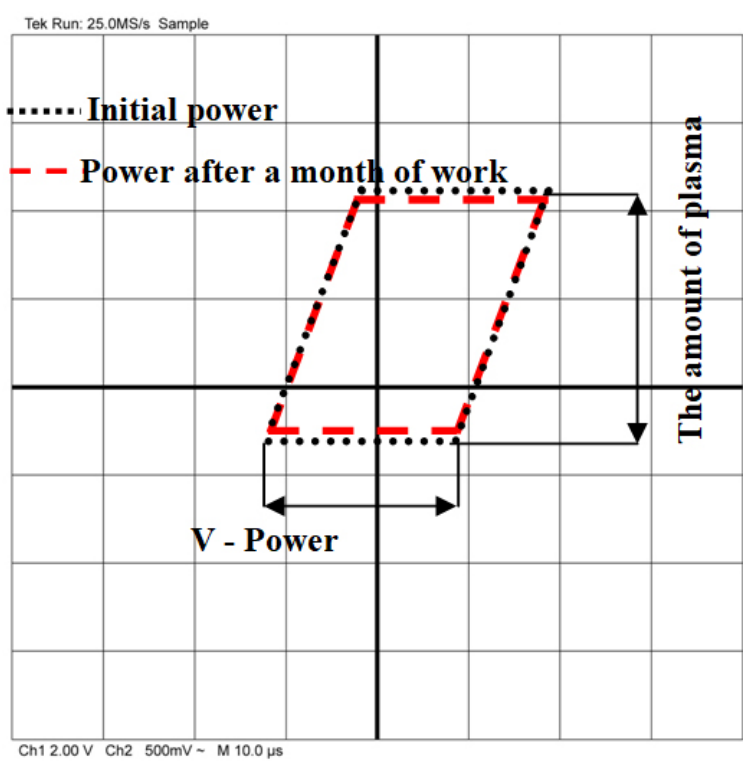

Fig. 3. Lissajous figures on the first day of work and after a month of reactor operation

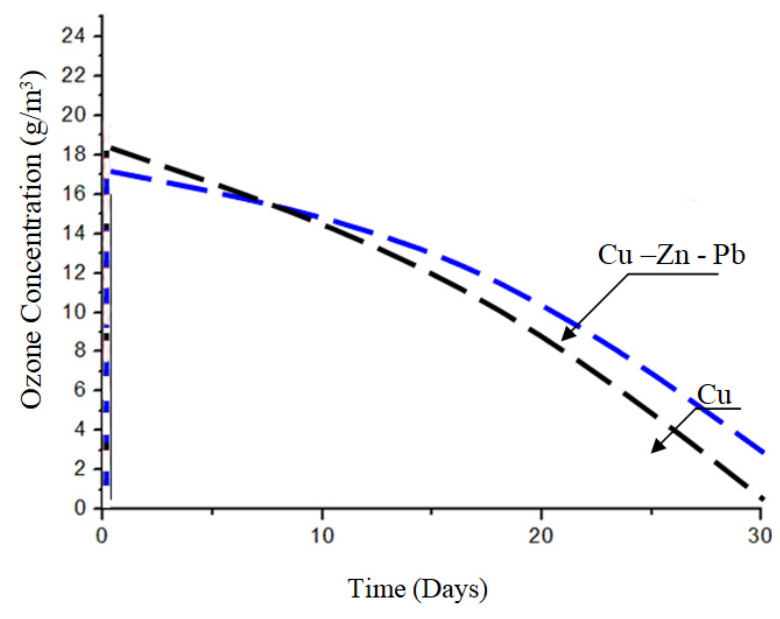

Fig. 4. Relationships between ozone concentration and electrode working time

in the surface condition of the electrodes used and the decreases in the concentration of ozone produced in Figure 1, 2.

Before use, the electrodes were characterized by a shiny surface characteristic for the materials used, namely: copper and copper alloy $(\mathrm{Cu}-\mathrm{Zn}-$ $\mathrm{Pb})$ - Figure 1.

After one month of operation, the electrodes made of copper and $\mathrm{Cu}-\mathrm{Zn}-\mathrm{Pb}$ alloy had a matt surface with a dark coating indicating the presence of a layer of oxidation products - Figure 2.

Another effect was the decreasing concentration of plasma (ozone) produced on the registered Lissajous figures (Figure 3) and on the curves of the ozone concentration over time - Figure 4. 
Table 1. Chemical composition of a copper electrode

\begin{tabular}{|c|c|c|c|c|c|c|c|}
\hline \multirow{2}{*}{ Copper } & \multicolumn{7}{|c|}{ Concentration of elements by $\%$ weight } \\
\hline & $\mathrm{Cu}$ & $\mathrm{Bi}$ & 0 & $\mathrm{P}$ & $\mathrm{Pb}$ & $\Sigma$ & No inclusions \\
\hline $\begin{array}{l}\text { CWOO4A* } \\
\text { CuETP** }\end{array}$ & $\geq 99.9$ & $\leq 0.0005$ & $\leq 0.04$ & --- & $\leq 0.005$ & $\leq 0.03$ & $\mathrm{Ag}$ i O \\
\hline
\end{tabular}

Table 2. Chemical composition of a copper alloy electrode $(\mathrm{Cu}-\mathrm{Zn}-\mathrm{Pb})$

\begin{tabular}{|c|c|c|c|c|c|c|c|}
\hline \multirow{2}{*}{ Alloys } & \multicolumn{7}{|c|}{ Concentration of elements by \% weight } \\
\cline { 2 - 8 } & $\mathrm{Cu}$ & $\mathrm{Pb}$ & Almax & Femax & $\mathrm{Ni}$ & Snmax & $\mathrm{Zn}$ \\
\hline $\begin{array}{c}\text { Cu-Zn-Pb } \\
\text { C34000 wg. EN } \\
\text { CW600N wg. ISO }\end{array}$ & $62.0-64.0$ & $0.8-1.6$ & 0.05 & 0.1 & 0.3 & 0.1 & rest \\
\hline
\end{tabular}

The aim of the experiment was to determine the structural effects of the chemical corrosion of the surface of rotating electrodes operating in the environment of dynamic oxygen flow and ozone in an electric field of a defined intensity.

The experimental material consisted of electrodes made of solid copper and of copper alloy $(\mathrm{Cu}-\mathrm{Zn}-\mathrm{Pb})$, Chemical composition of the electrode materials is given in Tables 1 and 2 .

The examined electrodes in the form of rollers with a length of $100 \mathrm{~mm}$ and a diameter of 10 $\mathrm{mm}$, had on the one hand an internal thread M6, and on the other, a hole $\varnothing 6 \mathrm{~mm}$ with a milling for a fastening wedge on the drive shaft.

In order to determine the structure of materials used for electrodes and to comprehensively evaluate the metallographic effects of chemical corrosion on the surface of electrodes occurring during the plasma generation process, experiments were carried out using light microscopy, scanning electron microscopy and X-ray phase analysis.

Metallographic microscopic examinations were carried out on the material cut off from the electrodes after their 30-day operation. The cut material was embedded in a self-hardening resin and ground mechanically on aqueous abrasive papers. Polished teeth were polished mechanically using diamond pastes with different granulation. Polished copper and $\mathrm{Cu}-\mathrm{Zn}-\mathrm{Pb}$ alloys were cut in an iron chloride based reagent. Metallographic observations and grain surface measurements were performed using the OLIMPUS GX71 reflecting optical microscope using a computer image analysis system using magnification from 100 to $2000 x$.
$\mathrm{X}$-ray experiments carried out with the diffractometric method included a qualitative X-ray phase analysis of the electrode surface after thirty days of use in a plasma generator. Electrode Xray examinations were carried out using an Empyrean X-ray diffractometer from PANalytical. The experiments were carried out using a parallel beam technique in a configuration with a Pixcel detector Co08Keta cobalt anode at $35 \mathrm{kV}$ voltage and $25 \mathrm{~mA}$ anode current. $\mathrm{X}$-ray, qualitative phase analysis was carried out in the range of $2 \theta$ angles from $10^{\circ}$ to $100^{\circ}$ corresponding to the inter-planar distances between $1.027 \mathrm{~nm}$ and $0.11168 \mathrm{~nm}$. The experiments ensured the conditions of the experiment in which the resulting diffractograms represent the material of the surface layer of the investigated electrodes. The phase composition of the layers formed on the surface of the investigated electrodes was identified based on the database of the International Center for Diffraction Data PDF - 4 + version 2015.

A scanning microscope was used to assess the structure of the electrodes, as well as the chemical composition in micro-areas of raid layers formed as a result of the oxidation process. Observations were made on metallographic examinations using the SUPE 35 scanning electron microscope from the company ZEISS. In the research, a side detector and a lenticular detector were employed, using secondary electron detection. The chemical composition of the microareas of the raid layers was determined using the EDX system. The observation was carried out at an accelerating voltage of $20 \mathrm{kV}$ using a magnification up to 2000 times. 


\section{RESULTS}

Structural examinations of the electrodes were carried out by metallographic observation using light microscopy, X-ray microanalysis as well as phase analysis using scanning electron microscopy. The subject of the metallographic examinations was the assessment of the structure of the electrode material as well as the geometry of the raid layers on the surface of the electrodes after a month of operation in the plasma reactor. The determination of the phase composition of the raid layers and their chemical composition in the micro-areas required the use of X-ray diffraction and the MAR method with high resolution.

The results of metallographic observations using light microscopy were included in micrographs - Figure 5-7, 11, 12. X-ray results were

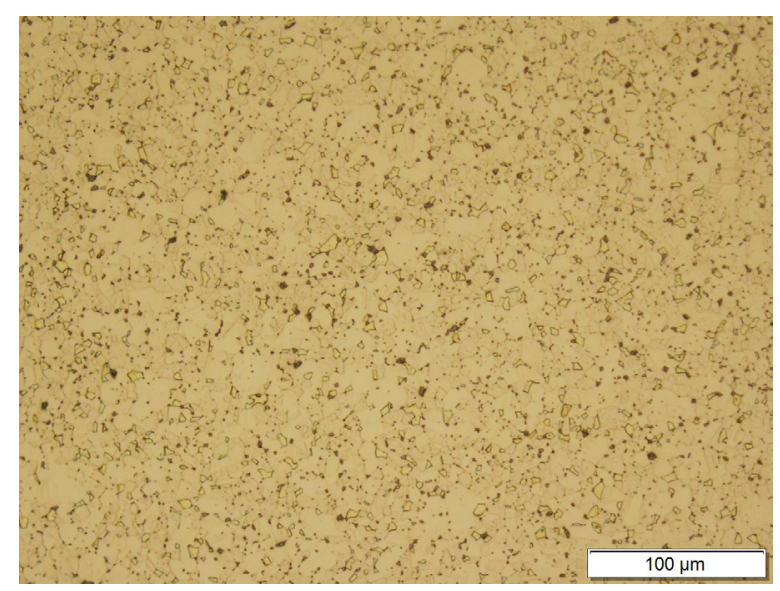

Fig. 5. Heterogeneous phase $\alpha$ grains with lead separations in the $\mathrm{Cu}-\mathrm{Zn}-\mathrm{Pb}$ electrode structure

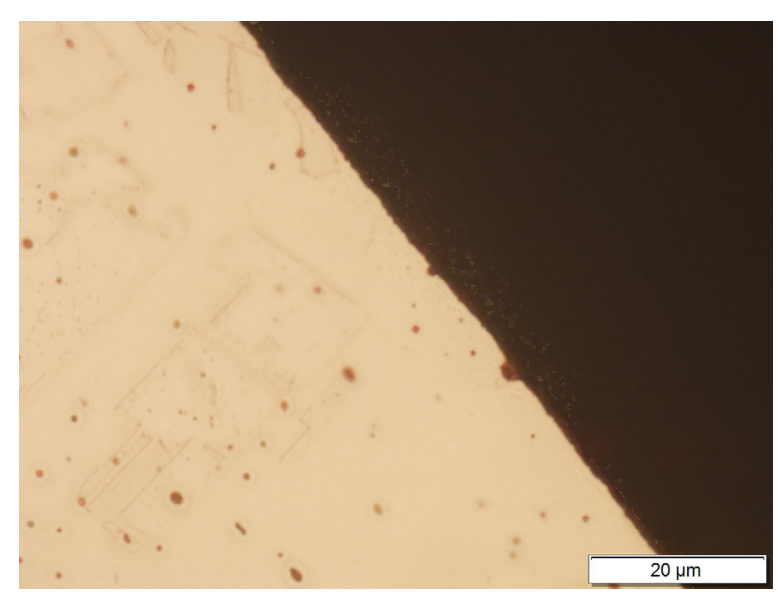

Fig. 6. Discontinuous raids layer on the surface of the $\mathrm{Cu}-\mathrm{Zn}-\mathrm{Pb}$ alloy electrode (lateral transverse) presented on diffractograms - Figure 11, 16 and microanalysis made using the EDX attachment, scanning electron microscopy on micrographs (Figure 8, 9, 13, 14) and diagrams (Figure 10, 15) and in Tables 3, 4.

According to the results of metallographic examination it was found that the layers occurring on the electrodes subjected to corrosive action of the aggressive environment of oxygen and ozone during a month of operation in the plasma reactor, whose thickness does not exceed $10 \mu \mathrm{m}$, are characterized by geometry corresponding to the raid layers. The electrode made of $\mathrm{Cu}-\mathrm{Zn}-\mathrm{Pb}$ alloy has a two-phase structure of non-homogeneous phase $\alpha$ particles ( $\mathrm{Zn}$ solution in $\mathrm{Cu}$ ) and pure lead in the form of precipitates - Figure 5, 6, 7. The average particle size of the $\alpha$ phase is from about 4 to $20 \mu \mathrm{m}$, and pure lead precipitations from about 1 to $4 \mu \mathrm{m}$ - Figure 8 .

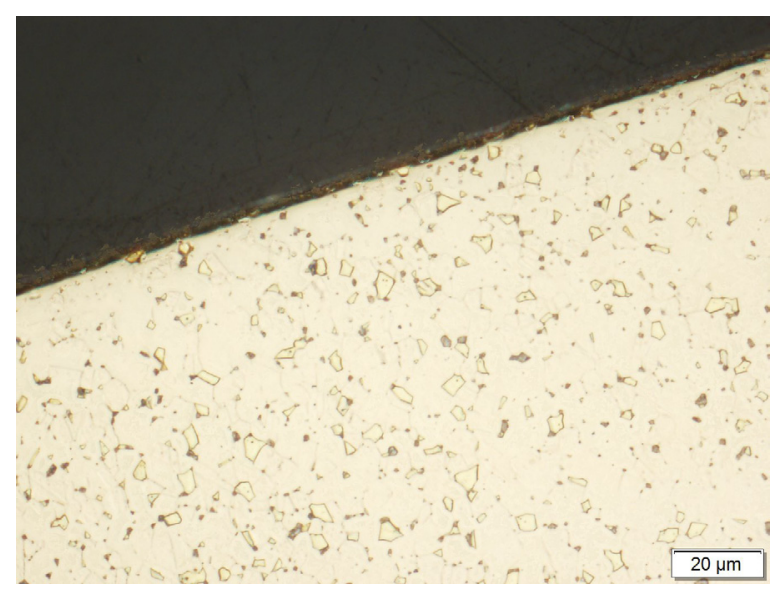

Fig. 7. Discontinuous raids layer on the surface of the $\mathrm{Cu}-\mathrm{Zn}-\mathrm{Pb}$ electrode (longitudinal ripple)

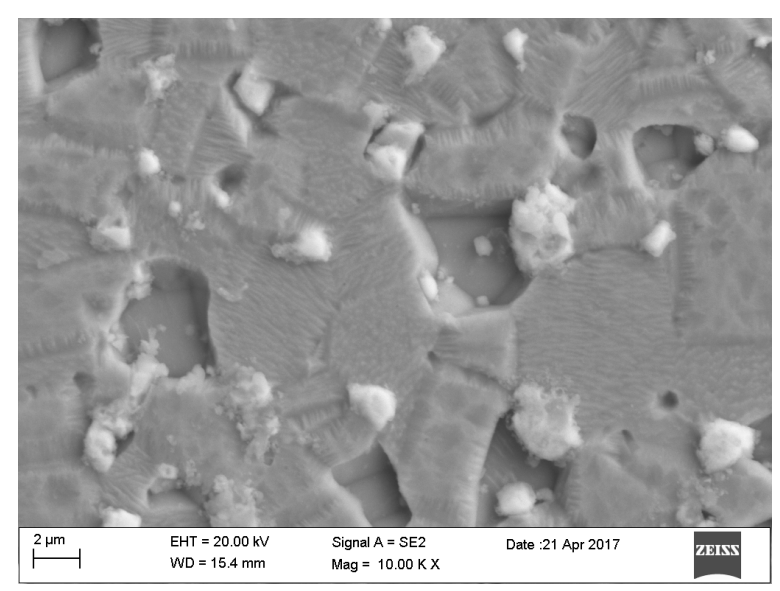

Fig. 8. A phase grains with lead separations in the structure of a $\mathrm{Cu}-\mathrm{Zn}-\mathrm{Pb}$ alloy electrode 
Table 3. Results of quantitative chemical microanalysis in the raids layer of the $\mathrm{Cu}-\mathrm{Zn}$ - $\mathrm{Pb}$ electrode at the points marked in Figure 9

\begin{tabular}{|c|c|c|c|c|c|c|c|c|}
\hline \multirow{3}{*}{ Element } & \multicolumn{8}{|c|}{ Point } \\
\hline & \multicolumn{2}{|c|}{1} & \multicolumn{2}{|c|}{2} & \multicolumn{2}{|c|}{3} & \multicolumn{2}{|c|}{4} \\
\hline & $\%$ weight & $\%$ weight & $\%$ weight & $\%$ atom & $\%$ wag & $\%$ atom & $\%$ wag & $\%$ atom \\
\hline $\mathrm{OK}$ & 22.56 & 46.15 & 33.45 & 56.87 & 18.69 & 43.44 & & \\
\hline AlK & 17.68 & 21.44 & 22.99 & 23.18 & 06.46 & 08.46 & & \\
\hline SiK & 02.67 & 03.11 & 01.97 & 01.91 & 01.53 & 01.60 & & \\
\hline CaK & 00.78 & 00.63 & 01.87 & 01.27 & 01.17 & 01.08 & & \\
\hline CuK & 33.72 & 17.36 & 20.66 & 08.84 & 40.79 & 23.87 & 57.65 & 61.25 \\
\hline ZnK & 22.59 & 11.31 & 19.06 & 07.93 & 40.79 & 14.71 & 35.31 & 36.46 \\
\hline $\mathrm{PbL}$ & & & & & & & 07.04 & 02.29 \\
\hline SK & & & & & 05.52 & 06.40 & & \\
\hline
\end{tabular}
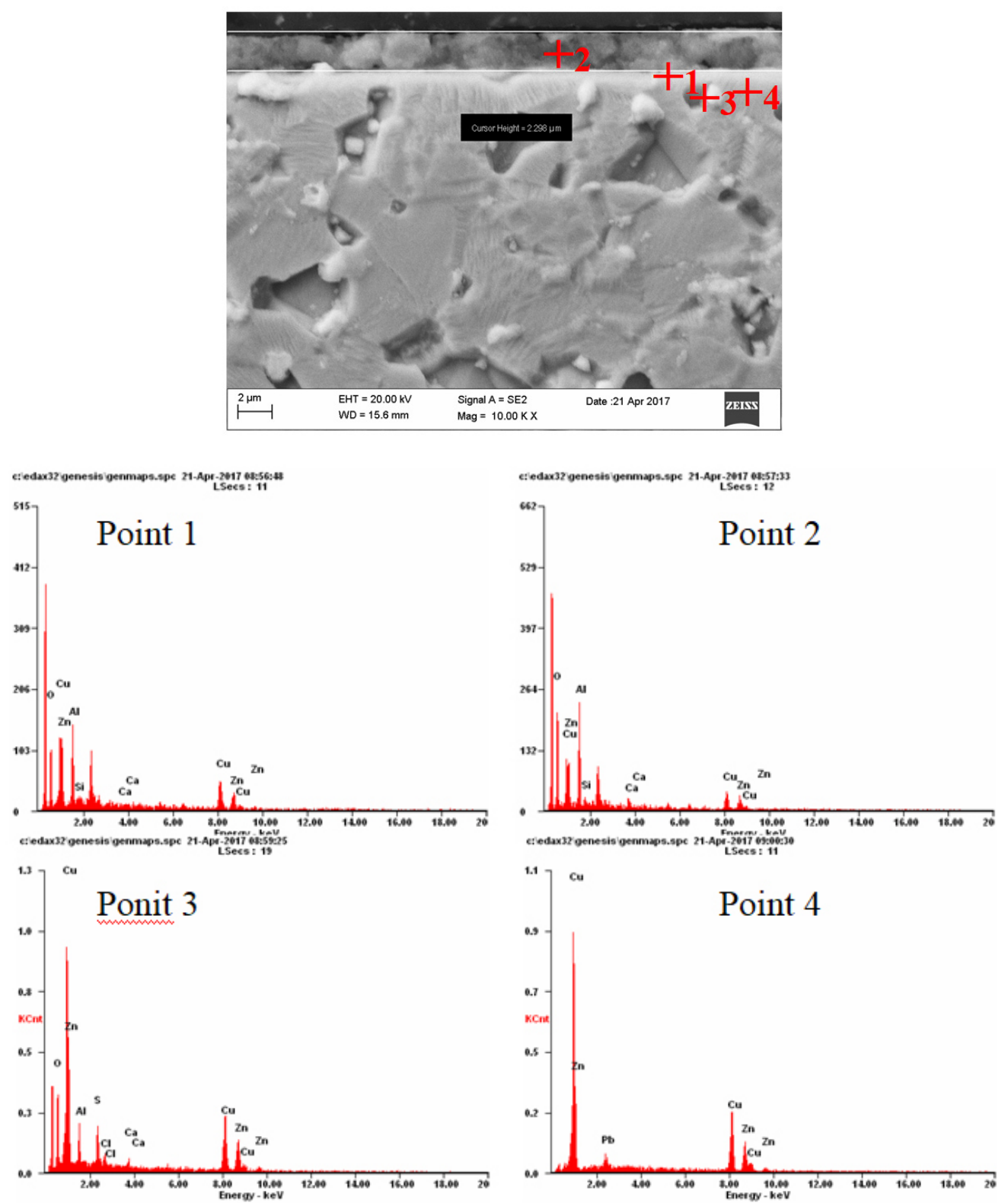

Fig. 9. Results of point chemical microanalysis in the raids layer (point 1,2,3) in the $\mathrm{Cu}-\mathrm{Zn}-\mathrm{Pb}$ electrode material (point 4) 


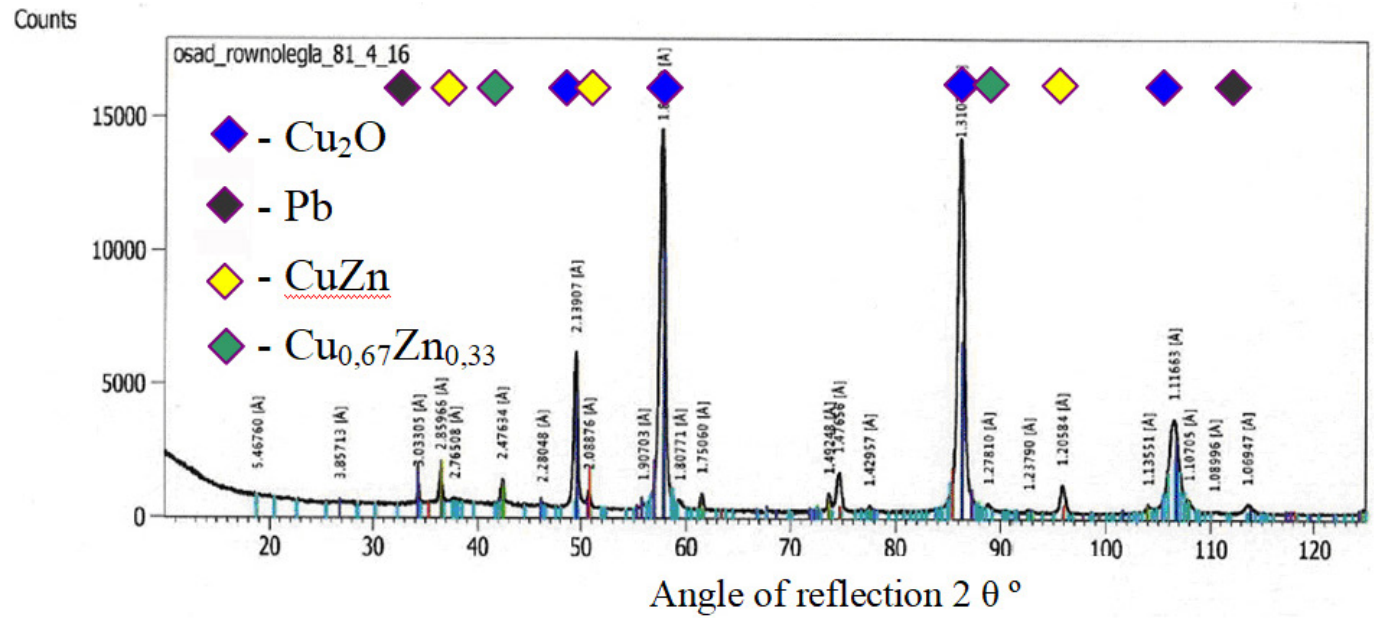

Fig. 10. The diffractogram of the surface of the $\mathrm{Cu}-\mathrm{Zn}-\mathrm{Pb}$ alloy electrode

After a month of use, chemical corrosion products on the surface of the electrode form a discontinuous raids layer with a thickness of 2.3 to $4.0 \mu \mathrm{m}$ observed on lateral and longitudinal deflections - Figure 6, 7.

On the diffractogram made from the surface of the electrode there are diffraction lines originating from copper, lead, copper oxide and copper-zinc compounds ( $\mathrm{CuZn}, \mathrm{Cu} 0,67 \mathrm{Zn} 0,33)$ - Figure 10. The maximum number of diffraction lines with the highest intensity is observed from the surfaces of the $\mathrm{Cu}_{2} \mathrm{O}$ oxide phase, which indicates the majority of this phase in the layer under investigation. Diffraction lines originating from copper-zinc compounds $(\mathrm{CuZn}, \mathrm{Cu} 0,67 \mathrm{Zn} 0,33)$ and small ones from pure lead are also characterized by high intensity - Figure 15.

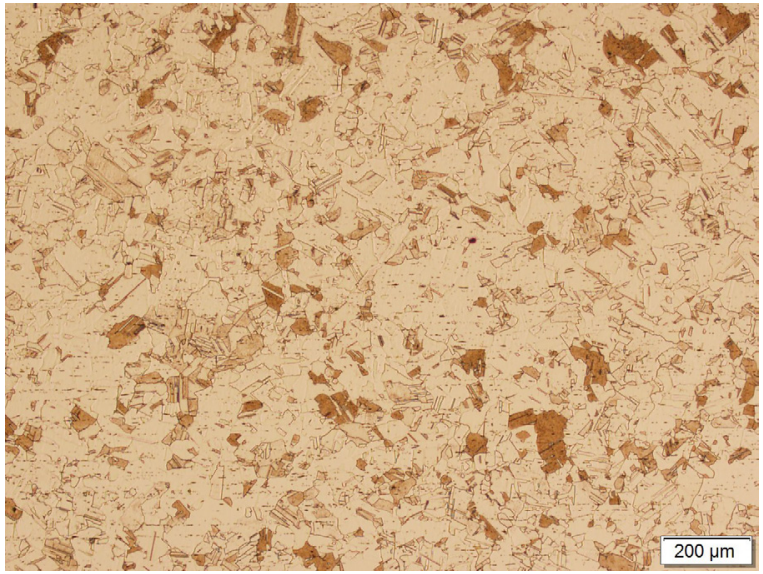

Fig. 11. Grains with twins in the structure of a copper electrode
Microanalysis in micro-areas of the raids layer of the investigated electrode allows it to be stated that in its chemical composition there are elements such as oxygen, copper, zinc and $\mathrm{Al}, \mathrm{Si}, \mathrm{Ca}$, the amount of which is shown in Table 3.

The highest oxygen concentration of $56.87 \%$ occurs at the boundary layer of the atmospheric layer of ozone and oxygen. As the distance from this limit increases to the electrode material, the oxygen concentration decreases significantly from $56.87 \%$ to $43.44 \%$ with increasing content of copper and zinc. The elements $\mathrm{Al}, \mathrm{Si}, \mathrm{Ca}$, present in small amounts, appear in microanalysis, and their presence is probably an effect associated with the preparation of the experiments.

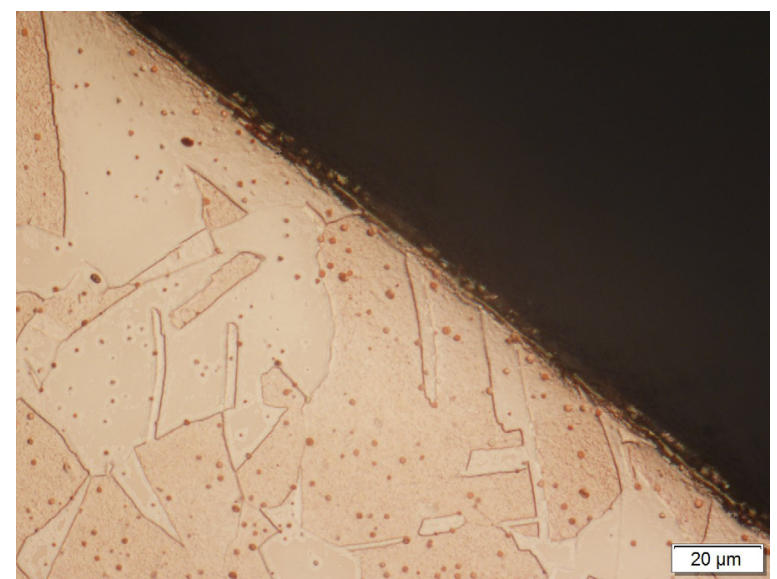

Fig. 12. A discontinuous raids layer on the surface of a copper electrode 


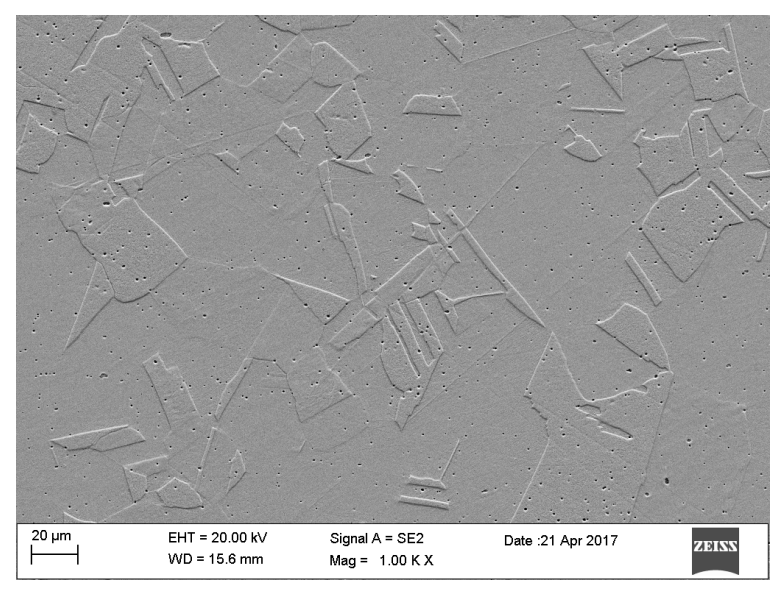

Fig. 13. Displaced $\mathrm{Cu}$ grains in the structure of a copper electrode

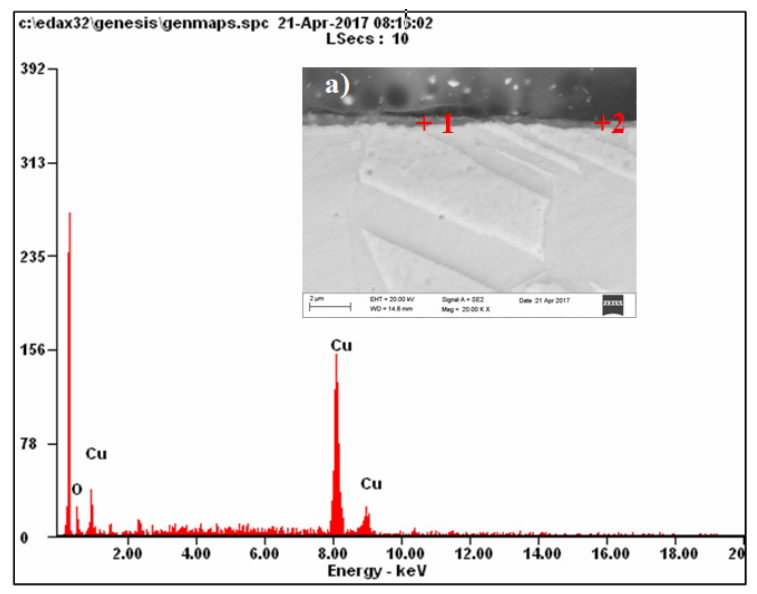

Fig. 14. Results of microanalysis of the chemical composition from area 2 marked on the micrograph (a), (Cu electrode)
The structure of the electrode made of copper indicates the annealed condition of the material - Figure 11 - 12. The material is characterized by grains with average surface area in the range from 0.02 to $0.06 \mathrm{~mm} 2$, inside which there are numerous twins - Figure 11 . Oxidation products are located on the surface of the electrode in the form of a discontinuous raids layer - Figure 12. The thickness of the observed layer is from about $0.89 \mu \mathrm{m}$ to $2.70 \mu \mathrm{m}$ - Figure 12. The phase composition of this layer was determined on the basis of $\mathrm{X}$-ray quality analysis - Figure 15 .

On the diffractogram made from the surface of the $\mathrm{Cu}$ electrode, the presence of diffraction lines of high intensity originating from the copper planes and of lower intensity than the surfaces of the $\mathrm{Cu} 2 \mathrm{O}$ oxide was found. The presence of oxygen and copper was found in the chemical composition of the raids layer analyzed point wise. In the analyzed points 1 and 2 , the oxygen concentration is $12.84 \%$ and $10.41 \%$ respectively - Figure 14, Table 4 .

Table 4. Results of the quantitative microanalysis of the chemical composition in the areas of the raids layer on the copper electrode, marked on the photomicrographs (a) - Fig. 14.

\begin{tabular}{|c|c|c|c|c|}
\hline \multirow{2}{*}{ Element } & \multicolumn{4}{|c|}{ Point } \\
\cline { 2 - 5 } & \multicolumn{2}{|c|}{$\mathbf{2}$} & \multicolumn{2}{c|}{$\mathbf{2}$} \\
\cline { 2 - 5 } & $\%$ weight & $\%$ atom & \% weight & \% atom \\
\hline OK & 03,58 & 12,84 & 02,84 & 10,41 \\
\hline CuK & 96,42 & 87,16 & 97,16 & 89,59 \\
\hline
\end{tabular}

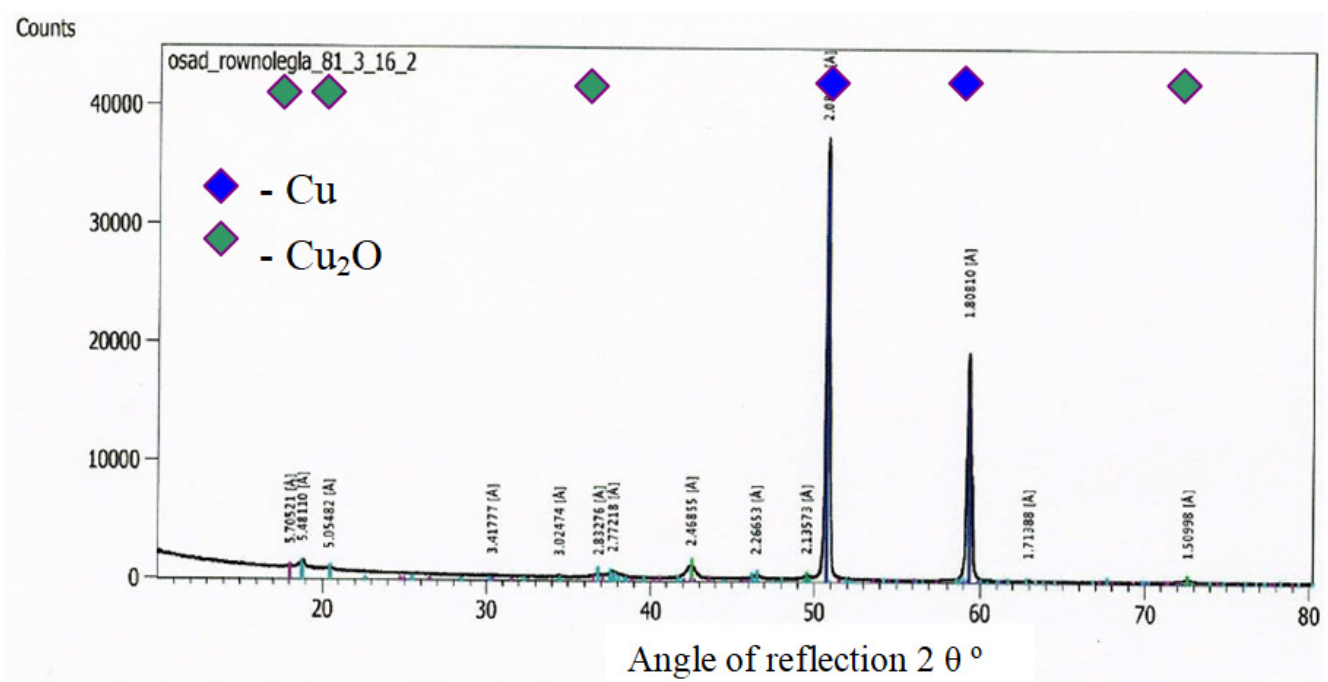

Fig. 15. A diffractogram from the surface of a copper electrode 


\section{CONCLUSIONS}

In the ozone production process, the plasma reactor electrode works in an aggressive environment of ozone being generated and oxygen being ionized and recombined. As a result of working in such conditions, the electrode is oxidized in the process of chemical corrosion. The dynamics of the plasma generation process and the type of electrode material working in changing process conditions are the decisive factors influencing the concentration of ozone produced. The influence of the medium, which is the electrode material, depends mainly on its resistance to corrosion in the environment of dynamically changing conditions, e.g. electrode rotation, oxygen flow through the rotating electric field and the month-long working time of the plasma reactor. The electrodes were made of materials characterized by similar corrosion resistance, namely $\mathrm{Cu}-\mathrm{Zn}-\mathrm{Pb}$ alloy and copper. Corrosion products formed on the surface of individual electrodes after 30 days of work in the plasma reactor showed different geometry, structure and chemical composition in the micro-areas of the raids layers. After one month of exploitation, corrosion products with a thickness of up to $20 \mu \mathrm{m}$, typical for raids layers have been found on the surface of the electrodes. On the surface of the electrode of $\mathrm{Cu}-\mathrm{Zn}-\mathrm{Pb}$ alloy and pure copper, the thickness of the resulting film is from approx. $4 \mu \mathrm{m}$ to $20 \mu \mathrm{m}$ respectively. The raids layers are characterized by discontinuities revealed both on longitudinal and lateral decouments - shade $6,7,12$.

\section{REFERENCES}

1. Brandes E. A., Brook G. B. Smithells Metals Reference Book. ISBN: 9780080517308, 2013.

2. Cygański A. Chemiczne metody analizy ilościowej. Wydawnictwo Naukowe PWN, ISBN 9788301194390, (2017).

3. Dobrzański L.A. Materiały inżynierskie i projektowanie materiałowe. Podstawy nauki o materiałach i metaloznawstwo, WNT, wydanie II zmienione i uzupełnione, Warszawa, 2006.

4. Dobrzański L.A. Metaloznawstwo opisowe stopów metali nie żelaznych. Wydawnictwo Politechniki Śląskiej, Gliwice, 2008.

5. Dobrzański L.A. Niemetalowe materiały inżynierskie. Wydawnictwo Politechniki Śląskiej, Gliwice, 2008.
6. Dobrzański L.A. Podstawy nauki o materiałach i metaloznawstwo. Materiały inżynierskie z podstawami projektowania materia owego, WNT, Warszawa, 2002.

7. Dobrzański L.A. Dobrzańska-Danikiewicz A.D. Obróbka powierzchni materiałów inżynierskich. Open Access Library 5 (2011), 1-480.

8. Dobrzański L.A. Metaloznawstwo z podstawami nauki o materiałach WNT, Warszawa, 2002.

9. Mrowiec S. Kinetyka i mechanizm utleniania metali. Wydawnictwo Śląsk, Katowice 1982.

10. Mrowiec S., Werber T. Korozja Gazowa Tworzyw Metalicznych. Wydawnictwo: Śląsk, 1965.

11. Praca zbiorowa, Poradnik galwanotechnika. WNT, Warszawa, 1985.

12. Gnapowski S., Gnapowski E. Effects of Rotating Electrode during Plasma Generation. ISBN 9783-659-51292-6, LAP Lambert Academic Publishing, (2014).

13. Gnapowski E., Gnapowski S. Changes in the power discharge in a plasma reactor using porous versus solid dielectric barriers and meshes electrodes", IEEE Transactions on Plasma Science, 2016, nr 10, vol. 44, 2079-2083.

14. Gnapowski S., Akiyama H., Hamid S. R. Hosseini, Yamabe Ch. Effect of Rotating Electrode. World Academy of Science, Engineering and Technology Research Journal, ISSN: 2010-376X Issue 0079/07/2013, International Science Index 79, 7(7), (2013), 1264-1271.

15. Gnapowski S., Akiyama H., Lenik K. New possibility for the use of plasma discharges to identify amber and changes in amber structure. Advances Science and Technology-Research Journal, ISSN 2080-4075, Vol. 6, 16/2012, (2012), 1-6.

16. Gnapowski S., Yamabe Ch., Ihara S. Ozone Generation Characteristics of Ozonizer with the Rotating Type Electrode. The Institute of Electrical Engineers of Japan, Vol.128, No.10, (2008), 619-623.

17. Gnapowski E., Gnapowski S., Pytka J., The impact of dielectrics on the electrical capacity, concentration, efficiency ozone generation for the plasma reactor with mesh electrodes, Plasma Science and Technology, 2018, nr 8, vol. 20.

18. Gnapowski E., Gnapowski S., Pytka J., The impact of dielectrics on the electrical capacity, concentration, efficiency ozone generation for the plasma reactor with mesh electrodes, Plasma Science and Technology, 2018, nr 8, vol. 20.

19. Gnapowski E., Gnapowski S., Pytka J., Effect of mesh geometry on power, efficiency and homogeneity of barrier discharges in the presence of glass Dielectric, IEEE Transactions on Plasma Science, 2018, nr 10, vol. 46, 3493-3498.

20. Pekarek S., Kriha V., Simek M., Balek R., Hanitz 
F. Hollow needle-to-plate electrical discharge at atmospheric pressure. Plasma Sources Science and Technology Vol. 8, (1999), 513-518.

21. Gnapowski E., Gnapowski S., Changes in the power discharge in a plasma reactor using porous versus solid dielectric barriers and meshes electrodes, IEEE Transactions on Plasma Science, 2016, nr 10, vol. 44, 2079-2083.

22. Gnapowski S., Akiyama H., Sakugawa T., Akiyama M., Effects of pulse power discharges in water on algae treatment, IEEJ Transactions on Fundamentals and Materials, 2013, nr 4, vol. 133, 198-204.

23. Gnapowski S., Gnapowski E., Duda A., Inproving of the quality food for animals by pulsed power plasma discharge, Advances in Science and Technology Research Journal, 2015, nr 27, vol. 9, 58-65.

24. Pekarek S., Rosenkranz J., Khun J. Ozone generation from two hollow needles to plate electrical discharges enhanced by airflow. Applied Physics, Vol. 37, (2004), 1214-1220. 